\title{
The Role of Self-Control on Mood States and Health Anxiety in a Sample of Blind and Visually Impaired People
}

\author{
Pierluigi Diotaiuti, Filippo Petruccelli, Luigi Rea, Angelo Marco Zona, Valeria Verrastro \\ Department of Human, Social and Health Sciences, University of Cassino and South Latium, Cassino, Italy \\ Email: p.diotaiuti@unicas.it
}

Received 4 November 2014; revised 1 December 2014; accepted 26 December 2014

Copyright (C) 2014 by authors and Scientific Research Publishing Inc.

This work is licensed under the Creative Commons Attribution International License (CC BY). http://creativecommons.org/licenses/by/4.0/

\section{(c) (i) Open Access}

\begin{abstract}
Blind people face daily a stressful condition that they seek to better manage through the control of the surrounding environment. They prefer the maintenance of routines and the contacts with familiar people and frequentation of well-known places. We hypothesize that in people with a serious visual impairment, the exercise of self-control, both as self-regulation both as coping of negative emotions, is significantly associated with the general tone of mood and can act as a protective factor with respect to the concern for their own health. The assumption underlying this study is that the levels of mood and self-rate of health concern are privileged indicators of the quality of life for blind people. 262 blind subjects were administered about personality inventory, scales for measuring resilience, the mood state, the anxiety about their health. Among the key findings, we noted that self-regulation was highly correlated to the mood of males, but only on the condition of acquired blindness, and that it could mediate anxiety levels with respect to their health. Self-esteem was not found to be a protective emotional factor for blind subjects. The study opens up the need to further investigate the capacity of self-regulation on the emotional sphere of people with disabilities in order to create more effective intervention programs to enhance the adaptive capacity of the subject.
\end{abstract}

\section{Keywords}

Self-Control, Self-Regulation, Mood States, Health Anxiety, Visually Impaired

\section{Introduction}

The loss of vision requires a significant psychosocial adaptation, a process with which many blind people are

How to cite this paper: Diotaiuti, P., Petruccelli, F., Rea, L., Zona, A. M., \& Verrastro, V. (2014). The Role of Self-Control on Mood States and Health Anxiety in a Sample of Blind and Visually Impaired People. Psychology, 5, 2218-2227. 
constantly fighting. The psycho-social impact of blindness and visual impairment is deep, as evidenced also by the high risk of depression, with high levels of emotional stress, and the negative impact on quality of life and overall health status. The visual impairment is usually associated with particular psychosocial conditions such as isolation, cognitive impairment, increased dependency on others, low self-assessment of health status, depression (Macfarland, 1966).

The visual limitation can increase the sense of vulnerability especially in the elderly, making them feel confined and imprisoned in their houses, deprived of important social interactions; this leads to some cases of depression, alcohol abuse and also of other substances (Graham \& Schmidt, 1999).

Generally the blind from birth seem more adapted to their condition and they show greater confidence in their own ability in carrying out every day practices, such as the use of public transport (buses, trains and subways); they also appear further integrated within a culture blind (Heyl \& Wahl, 2001).

At contrast, those who become blind as a result of a sudden event (illness or injury), become immediately aware of a rapid transition to status of an individual considered generally unable to perform even simple tasks and activities. Living with an important functional limitation such as sight, constantly imposes the task of preserving the residual skills. It also includes the exposure to risks and challenges when coping strategies cease to function, or for a deterioration of functional limitation or because of environmental barriers outside the control of the subject. The work of adaptation could be represented as a route consisting of several phases (recognition, exploration, re-acquisition, maintenance) but not necessarily a continuous process from one step to another (the length may be longer or shorter and in some cases the subject may stop and go back) (Bergeron \& Wanet-Defalque, 2013; Diotaiuti, 2011).

Blind and visually impaired people live in a naturally stressful condition, which are constantly engaged in research and conservation of the control of environmental conditions, with a preference for the maintenance of routine and relations with familiar people and well known places. It is possible to find an explicit or implicit fear in front of the possibility of unexpected change of stable frames of reference. Many have learned by the time how to best manage this fear, however, that re-emerges with all its anxiety, in cases of emergency or sudden change (Verstraten et al., 2005). Blind people who are more ready often react to the frustrations with outbursts of anger; this is a positive factor because it means an orientation to the relationship that allows individual to direct the stress. Others, however, are closed in themselves, in a completely passive way, excluding the possibility of a reaction externally oriented.

The risk of depression, especially in elderly blind and visually impaired people can be reinforced by other factors, such as the negative perception of the quality of life, poverty and other health problems less important than visual impairment (Kemp, 2000). Depression is manifested by changes in mood and behavior, lack of motivation, digestive problems, weakness, persistent irritability and sadness, deficit in memory and inability to properly relate to others (De Leo et al., 1999). For some people alcohol abuse may be a form of adaptation and coping with the new disability and may provide temporary relief but actually this increases social isolation over time and weakens coping skills, influencing the onset of new health disorders.

Perceptions of self-efficacy play a key role in the management of chronic diseases. They will determine whether an individual will seek to implement new behaviors strongly oriented to health (Holman \& Lorig, 1992; Clark \& Dodge, 1999). Lazarus and Folkman (1984) have identified two general types of coping. The first is defined problem focused coping and can be referred to the efforts made by patients to manage stress, actively intervening to change the source of stress. This strategy includes the problem definition, generation of alternatives, evaluation of alternative situations. The second type of coping is instead focused on emotions, including attempts to reduce or manage the emotional stress associated with the situation. This strategy involves minimization, distancing, selective attention, positive comparisons, looking for positive values in negative events, selfillusions, avoidance.

The problem-focused coping strategies are used when individuals consider the event modifiable or manageable, and when individuals recognize that the situation should simply be accepted, and they are likely to use emotion-focused strategies. This approach stresses that the way in which the patient reads their condition will influence the type of coping used, which in turn will determine whether an experience of psychological stress or acceptable quality of life will take place (Lazarus \& Folkman, 1984). The relationship between the evaluation of the disease, coping and adaptation is central in another model called social cognition model of self-regulation (Cameron \& Leventhal, 2003). The adjustment involves a modulation of thought, affect, behavior, attention, or the intentional use of specific mechanisms or automatic supportive meta-competencies. The self-regulating 
processes start when the subject is prevented from routine activity or when the orientation of the object changes its salience (e.g. the occurrence of a challenge, the failure of usual action models) (de Ridder \& De Wit, 2006). Various studies have emphasized the role that the subjective salience may have in the ability to exercise selfcontrol, and identified the mechanisms and strategies through which self-control can be activated in order to protect subject's important goals (van der Pligt \& de Vries, 1998; Levine, 2010).

In the light of these considerations, we hypothesize that people with a visual impairment the exercise of selfcontrol (both as a self-regulating, both as an exercise in the management of negative emotions) is significantly associated with the general mood tone and can act as a protective factor with respect to the concern for their own health. The assumption underlying this study is that the levels of mood and their health experience are privileged indicators of the quality of life for blind and visually impaired people. A well-known risk factor for mental health disorders frequently associated with many visual slow but progressive degeneration, is the so-called syndrome of the sword of Damocles. The individual lives in a constant state of anxiety and concern for their health but the greatest anxiety is due to the idea that, sooner or later, the residual vision will fade to make the person completely blind (Hayman et al. 2007). In this sense, individuals evaluate events as uncontrollable, feeling at their mercy and become passive, resigned, anxious and depressed. A positive mood disposition, especially the optimism, produces a significant increase in subjective well-being, understood also as favorable evaluation of their own existence (Wrosch \& Scheier, 2003).

According to Fredrickson (2001) the effects of positive emotions consist not only in the creation of a state of subjective well-being, safety, adaptation to their ecological niche, but would also serve to inhibit the harmful effects produced by negative emotions. They are therefore a kind of antidote to adverse outcomes generated by negative emotional experiences.

For this reason, we believe it is important to identify elements whose presence may facilitate the persistence of positive mood states. Self-control as well as to facilitate adaptation may prove to be associated with positive mood states.

Among different components of the self-control we have considered in particular the self-regulatory skills, the ability to cope with negative emotions, and resilience.

To sum up among the main goals we have set in our study is investigating relationships between personality features of blind subjects (such as self-esteem, social desirability, self-regulation, resilience and ability to cope) with the levels of mood and feelings of concern related to their health state.

\section{Methodology}

\subsection{Participants}

262 blind subjects randomly selected from the Italian centers of the "Italian Union of Blind and Visually Impaired” (Unione italiana dei Ciechi e degli Ipovedenti-UICI): 154 males and 108 females, with an average age between 46 and 60 years old.

\subsection{Instruments}

1) Multidimensional Personality Profile (MPP) standardized by GV Caprara et al. (2006). It is a tool that allows highlighting the skills of individual adaptation to life situations, even enabling to get any indication about future behavior in terms of psychological well-being. In particular, the key areas of personality measured by MPP are five:

a) Agency: Enforcing their views, setting itselves ambitious goals, to know how to lead and motivate others, in conducting its activities with vigor and alertness. It consists of: Identification, Ambition, Leadership, Business.

b) Social and emotional intelligence: Individual skills that manifest in empathy, emotional intelligence and a general trusting orientation toward others and relationships. The related sub-dimensions are: Empathy, pro-sociality, Sociability, Interpersonal Trust.

c) Self-regulation: Individual skills related to the planning and persistence in achieving a goal, self-discipline meaning both self-reflexive organization skill and tenacity to success. It is divided into sub-areas: Actionoriented, Tenacity, Reliability, Accuracy.

d) Coping Ability (in critical situations): Emotional balance as mood stability, the efficient management of 
stress, frustration and adversities, in the management of negative emotions, and the resilience and strength against events that cause discomfort and disappointment. It consists of: Emotional balance, Stress Management, Management of negative emotions, Elasticity/Resilience.

e) Innovation: This dimension is embodied in the interest and curiosity about cultural activities and individual skills such as creativity and the pleasure towards new situations and solutions. Next to the five areas above, there are four scales for examining self-presentation: Self-esteem, social desirability, "Machiavellianism”, management of their thought (about the others).

2) Resilience Scale for Adults-RSA (Friborg et al., 2005) consists of 33 items distributed across six factors measured through three subscales: social skills, structured style and personal strength that is in turn made up of two factors, self-perception (how the individual perceives his current skills and strengths) and planning for the future (how the individual sees the opportunity to achieve their goals in the future). The support and family cohesion and external support are measured respectively by the family cohesion subscale and the subscale social resources.

3) To estimate the level of mood owned by individuals (humoral self appraisal) we have created a self-assessment checklist on a 6-point Likert scale in which the subject was asked to define his level of humor. The points of the scale were coded as: a) extremely low; b) low most of the time; c) more low then high; d) more high then low; e) in a good mood; f) excellent mood. It was required the subject to refer to the two weeks preceding the interview.

4) For the estimation of concern for their own health, we created a self-assessment checklist on a 6-point Likert scale in which the subject was asked to indicate how much his state of health aroused concern. Respectively, the points of the scale were coded as: a) for nothing; b) a little; c) enough; d) a lot; e) very much; f) enormously. All the instruments described above were administered orally by properly trained operators.

\subsection{Procedure}

The specific conditions of the protagonists of the investigation led to the administration of the instruments by interviewers specifically trained in order to don't distort detection. The meetings took place in presence, at home or in the associative structures, by appointment, in which each respondent was available for an hour, specifically and exclusively for the survey.

Participants were informed about the aims of the study and their participation was free. The questionnaires were anonymous and self-administered. The study protocol complied fully with the guidelines of the Ethics Committee of the Cassino University of South Lazio and was approved by the Institutional Review Boards in accordance with local requirements. It was conducted in accordance with the Good Clinical Practice guidelines and the Declaration of Helsinki (1964) and subsequent revisions. After receiving information about the study, all the subjects provided written informed consent.

\subsection{Statistical Analysis}

The analyzes were conducted with the statistical package SPSS (version 20.0). When the studied variable had a normal distribution in the population from which the sample was extracted, we used the Student's test to compare two independent means. When the studied continuous variable had not a normal distribution non-parametric tests were used. Significance level was set at $p<0.05$.

By subjecting all 152 items of the scale MPP to Reliability Analysis, the validity of the model used was confirmed, which has positive indices of reliability: Cronbach’ alpha $=0.89$. Even the RSA was confirmed to be a reliable scale with good internal consistency demonstrated by Cronbach's alpha values of 0.79 , while among the six factors, the range is from 0.67 (structured style) to 0.81 (self-perception). The correlation of the 33 items of the subscales is high. In order to examine the structure of the MPP and RSA used in this study we used the Principal Components Analysis (PCA) of the correlation matrix of the questions which compose the scales. In order to identify which questions more represented by which component we used as a criterion with a factor loading greater than 0.4. For the inclusion of a question in the model to be submitted to the Principal Components Analysis we used as a criterion the coefficient of determination $\left(\mathrm{R}^{2}\right)$ greater than 0.15 .

\section{Results}

As a first instance, we found that the overall sample of the blind compared with the normative, had high scores 
on the social desirability scale MPP. The scores of these subjects were all within high range. The women reported an average score of 61 , the men of 60 . With regard to the dimension of self-esteem, the scores of women fell within average range, while the scores of men fell within low range. With regard to the dimension of selfregulation, the scores obtained from both genders were part of the low range. With regard to the coping ability, for both males and females, scores fell within average range.

We examined then whether the condition of the onset of the disease (blind congenital or acquired), for $\mathrm{N}=$ 262 (Males: 154, Females: 108), average age $=$ 54.95, born blind and blind acquired: 122 and 140, was significantly associated with levels of mood self-appraisal. Statistical analysis revealed no significant differences in the mood levels in function of the condition of onset disease. We then verified the scores of self-regulation and the coping ability, as measured by the MPP according to the condition of the subjects. For both males and females, there were no significant differences on the scale of self-regulation and the coping ability among those blind at birth and those acquired. We then compared the group of subjects with positive mood with those with negative mood. There were statistically significant differences regardless to the condition of onset of disability and gender to the scores of the scale of coping ability. Positive mood: 76.8; negative mood: 71.8 (Sig, 0.001) (See Figure 1). The same significant differences emerged between the group that showed high concern for their health and the group who reported low levels (high concern group with a mean 72.9 and 75.8 the mean for low concern group-Sig, 0.013) (See Figure 2).

Comparing male subjects with positive mood and those with negative mood, there were statistically significant differences (Sig, 0.001) in average scores on the scale of self-regulation: positive mood 77.4; negative mood 73.9 (See Figure 3) and on the scale of resilience (RSA) (Sig, 0.002; 132 positive mood, negative mood 115) (See Figure 4).

Depending on the onset disease condition, only for males with acquired blindness, there was a significant difference (Sig, 0.001) to the scales of self-regulation (78 positive mood, negative mood 73) (See Figure 5), resilience (131.2 positive mood, negative mood 111.2) (See Figure 6) and coping ability (76.9 positive mood, negative mood 72.6).

For females there was a significant difference (Sig, 0.01) to the scale of resilience (RSA): average score of 127 positive and 110 negative mood (See Figure 7). Depending on the onset disease condition, the differences remain unchanged.

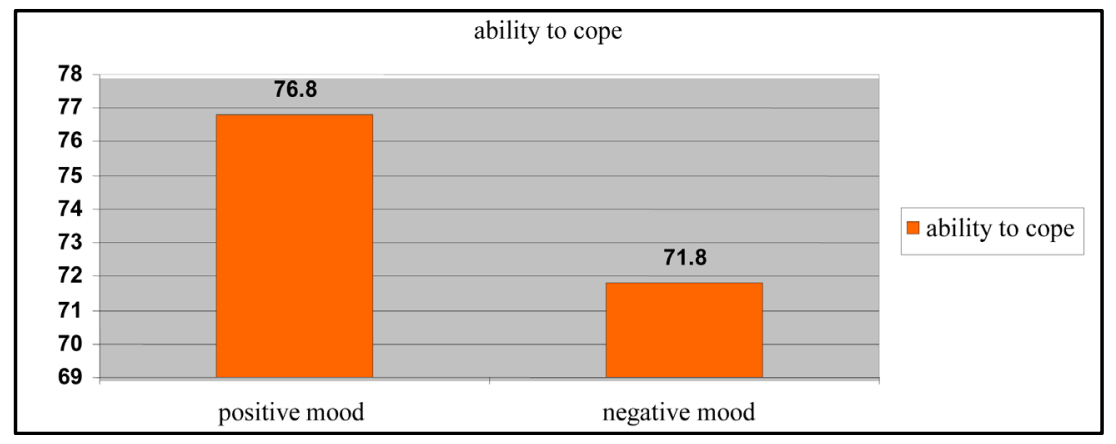

Figure 1. Ability to cope and mood.

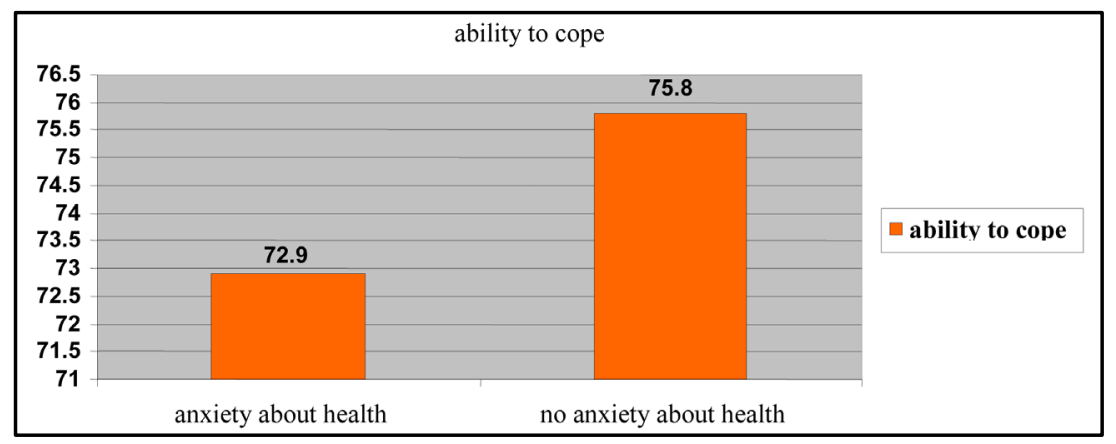

Figure 2. Ability to cope and health anxiety. 


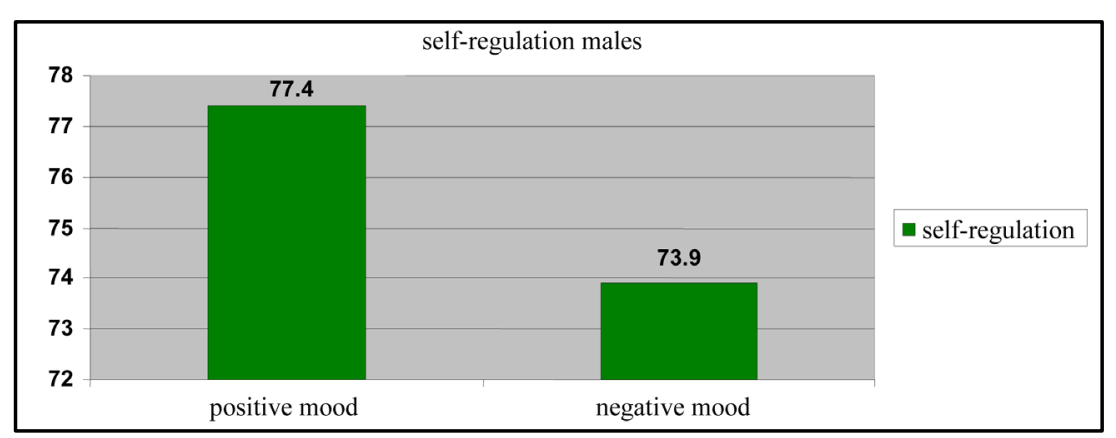

Figure 3. Self-regulation and mood in male blind.

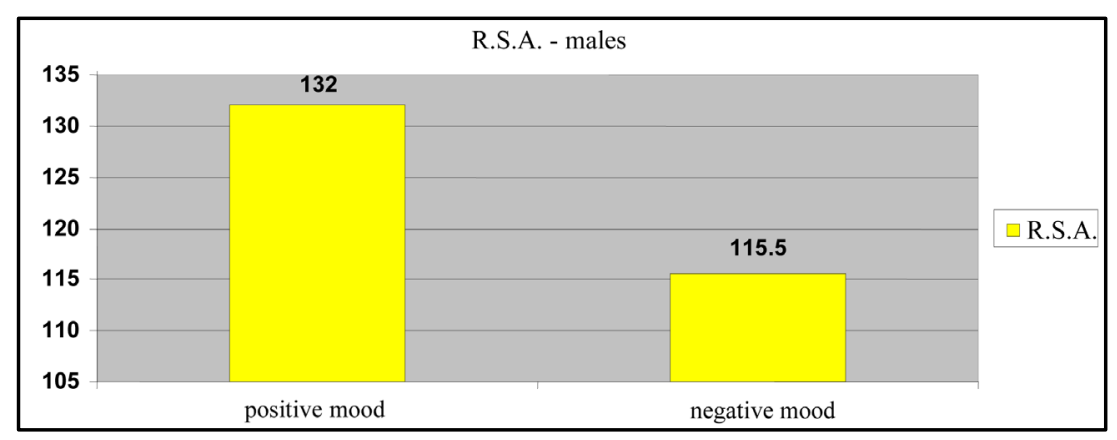

Figure 4. Resilience and mood in male blind.

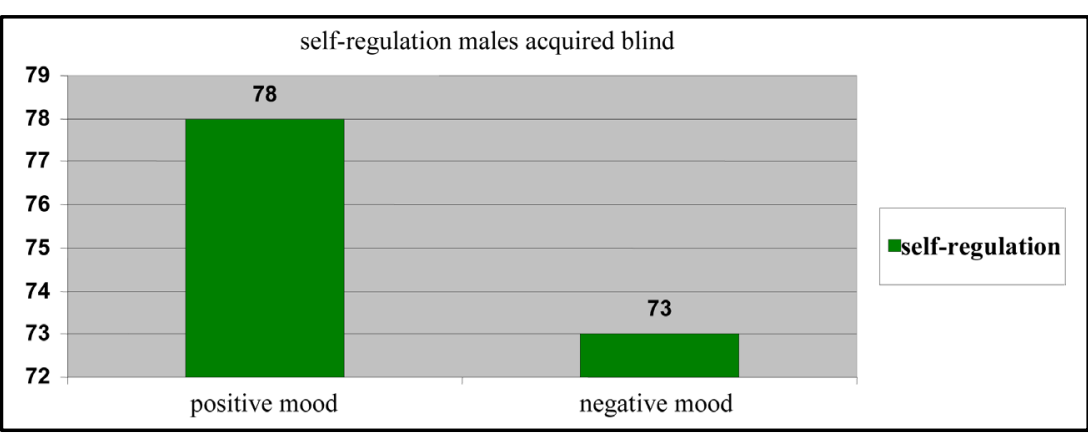

Figure 5. Self-regulation and mood in males acquired blind.

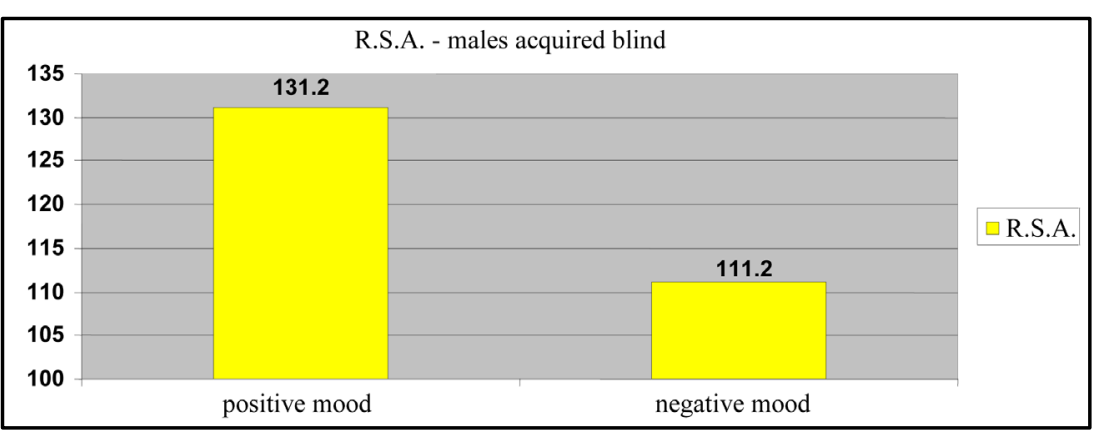

Figure 6. Resilience and mood in males acquired blind.

Another interesting information emerged by analyzing the sample of males born blind. In this group there were no significant differences to the scale of social desirability, among those who reported a positive mood than those who reported a negative mood (positive mood: mean 27.65—negative mood: mean 23.37; Sig, 0.05) (See Figure 8). 


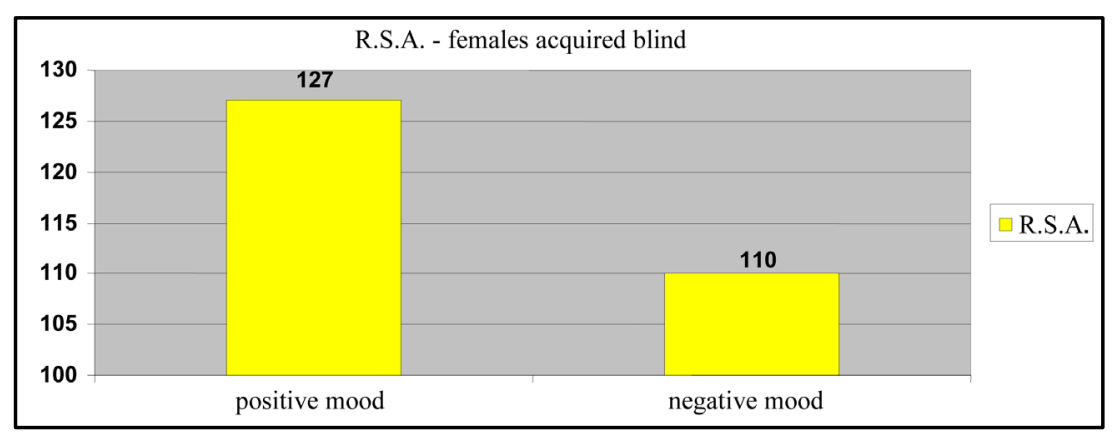

Figure 7. Resilience and mood in females acquired blind.

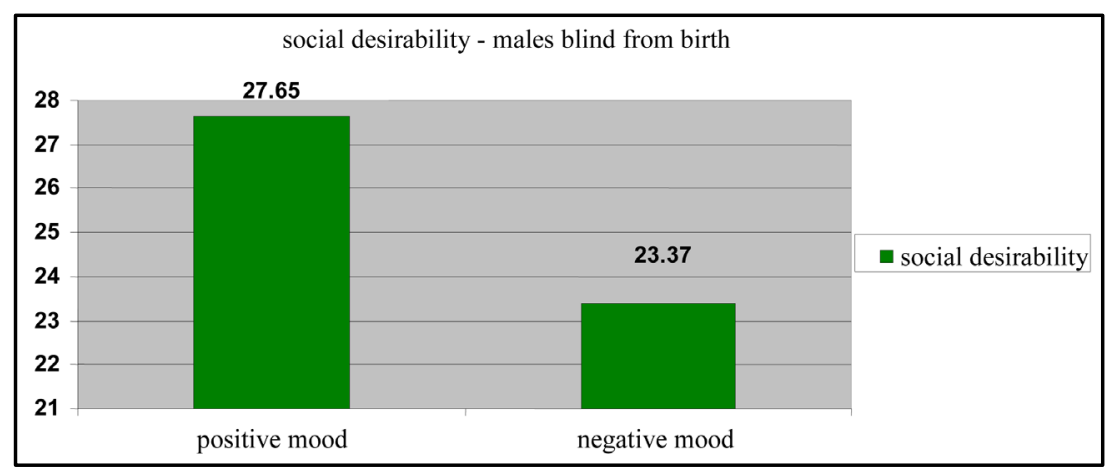

Figure 8. Social desirability and mood in males blind from birth.

By analyzing the sample in function of the concern about their health status, statistically significant differences appeared in average scores on the scale of self regulation. Those who showed high levels of concern about their own health status reported an average score to the scale of self-regulation significantly lower than those who showed low levels of concern (mean worried 74.9-not worried mean 76, 9; Sig, 0.01) (See Figure 9). Nevertheless, considering the variable self-esteem, there were no significant differences between those who showed high levels of concern for their health and those who showed low levels of concern (See Figure 10).

We then examined whether there were any significant differences in the scale of self-esteem among those who reported a positive mood and those who showed a negative mood. Considering the overall sample, according of both the gender and to the onset of disability, no statistically significant differences emerged (See Figure 11 and Figure 12).

\section{Discussion}

In the literature, self-esteem is universally considered a factor that mediates the impact of negative events on emotional life, promoting the activation of individual resources, that are useful to the preservation of the Self (Mann et al., 2004; Cott et al., 1999). In our study however the findings suggest to reconsider this proposal. In fact, among the blind population, considered in all experimental conditions and in spite of the gender, there were no significant correlations in this regard. This leads us to reconsider the weight of the dimension of self-esteem in emotional experience for blindness.

For all subjects, coping ability and resilience emerged as the most important personality characteristics for the process of mediation of emotional states, such as mood appraisal and levels of anxiety related to health status. By contrast, the ability of self-regulation has been shown highly positively related to mood among males, but merely in the condition of acquired blindness. This condition may reflect a particular experience of loss, in which the subject is required a greater ability to adapt and emotional and cognitive restructuring. This may be the reason why the skill of self-control plays a decisive role on the mood status. Positive mood would be promoted by the skills of individual self-regulation, even in the context. On the other way, for males who born blind, mood status was found to be associated with social desirability. It is evident that those who reported high score to the scale of social desirability, also reported a positive mood. 


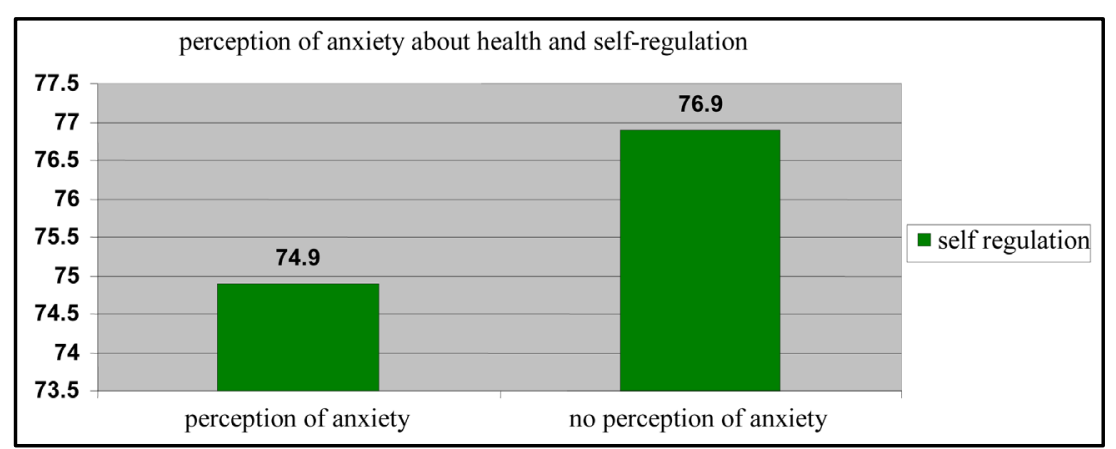

Figure 9. Self-regulation and health anxiety.

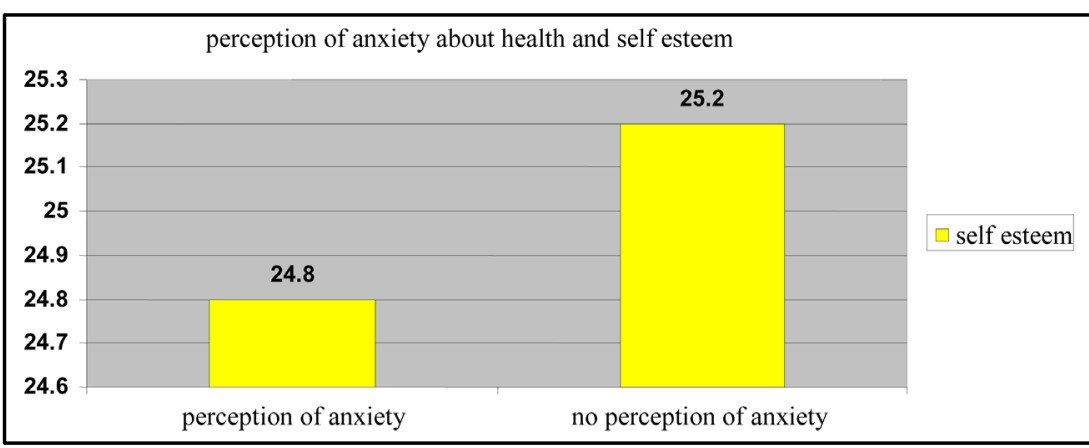

Figure 10. Self-esteem and health anxiety.

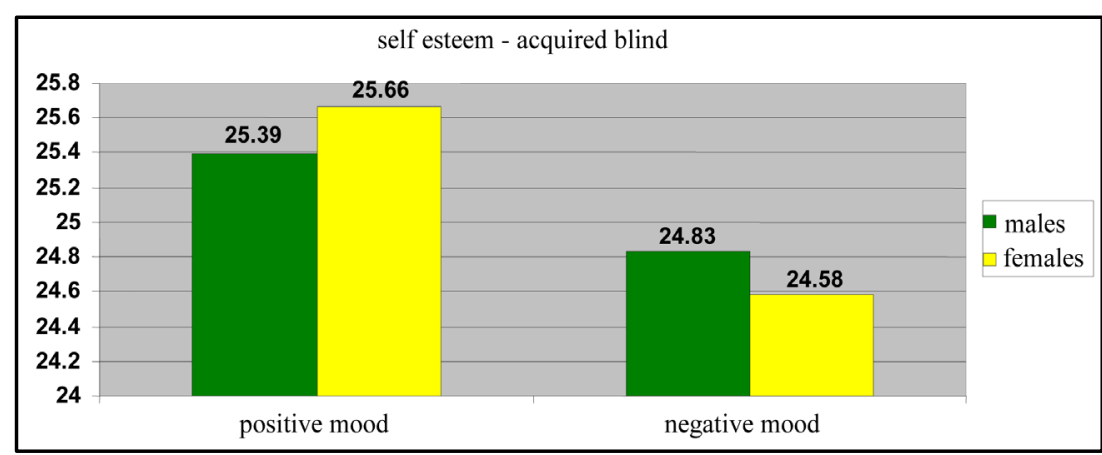

Figure 11. Self-esteem and mood in acquired blind.

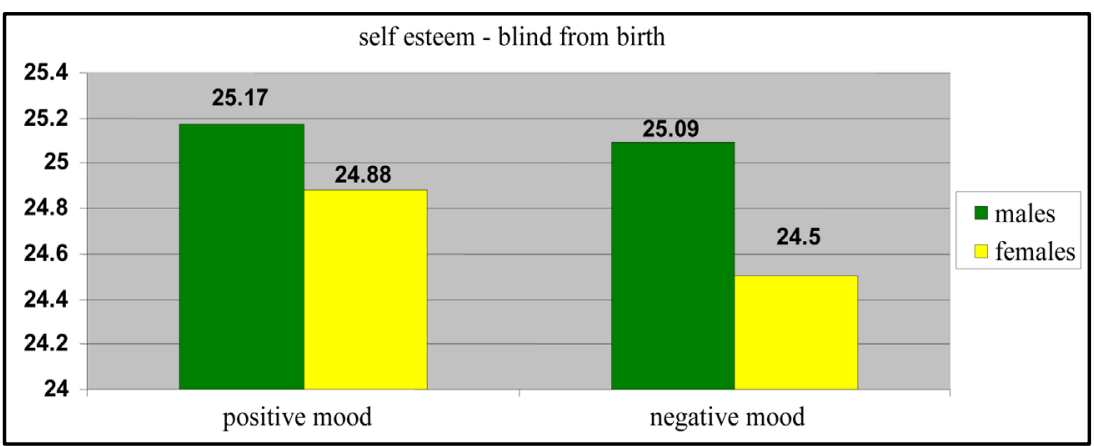

Figure 12. Self-esteem and mood in blind from birth.

The ability for self-regulation would appear to be crucial to mediate the experience of anxiety related to perception of individual health status. In this case, it is shown that those who have high ability for self-regulation, 
feel less concern about their state of health. Even in this case, self-esteem levels don't seem to have any influence. The study open to the need to further investigate the weight of the ability for self-regulation on emotional life in people with visual impairments, introducing also experimental conditions in which it is possible manipulate the levels of self-regulation, in order to produce intervention programs that are more effective to enhance individual ability of adapt.

\section{Conclusion}

The resilience and the coping ability were found to be protective emotional factors for the subjects in all experimental conditions. For males, the ability for self-regulation may be an important factor in order to protect the emotional experience among subjects in condition of acquired blindness, resulting in better levels of mood and quality of life. The ability for self-regulation may mediate anxiety levels concerning to their health. For women with acquired blindness, self control is not a factor of emotional protection. For males born blind, positive mood is associated with social desirability. In contrast to resilience, the ability for self-control is not related to mood levels in subjects with the condition of congenital blindness. In our study, self-esteem was not found to be an emotional protective factor in blind subjects. Based on the findings, we believe in agreement with Kef (2002), that a program of interventions aimed to strengthen social skills would produce significant improvements in well-being of these subjects. However, the work on social skills might not be quite enough to support the process of adaptation and well-being of the person who is blind or visually impaired. It would be appropriate to support and encourage the development of self-determined behavior, or the ability to define important goals for themselves and the ability to take the initiative to achieve those objectives. Educational and training interventions aimed at enhancing the intrinsic aspects (not just instrumental) of the motivations underlying the actions taken by individuals who are blind and visually impaired people may actively contribute to break the circuit of relational dependency and passivity that often characterize their sphere of social contact. When subjects take part in activities that they have freely chosen and over which they exercise control, intrinsic motivation increases and the level of perceived well-being with it. Through an intrinsically oriented motivation the interest among the activities, the need of competence, and the self-realization will persist even after reaching the goal (Deci \& Ryan, 2002). All this can contribute to the persistence of positive mood states.

\section{References}

Bergeron, C. M., \& Wanet-Defalque, M. C. (2013). Psychological Adaptation to Visual Impairment: The Traditional Grief Process Revised. British Journal of Visual Impairment, 31, 20-31. http://dx.doi.org/10.1177/0264619612469371

Cameron, L. D., \& Leventhal, H. (2003). The Self-Regulation of Health and Illness Behaviour. New York: Routledge.

Caprara, G. V., Barbaranelli, C., De Carlo N., \& Robusto, E. (2006). Multidimensional Personality Profile (MPP). Milano: FrancoAngeli. PMCid: PMC2786217.

Clark, N. M., \& Dodge, J. A. (1999). Exploring Self-Efficacy as a Predictor of Disease Management. Health Education Quarterly, 5, 371-379.

Cott, C. A., Gignac, M. A., \& Badley, E. M. (1999). Determinants of Self Rated Health for Canadians with Chronic Disease and Disability. Journal of Epidemiology and Community Health, 53, 731-736. http://dx.doi.org/10.1136/jech.53.11.731

De Leo, D., Hickey, P. A., Meneghel, G., \& Cantor, C. H. (1999). Blindness, Fear of Sight Loss, and Suicide. Psychosomatics, 40, 339-344. http://dx.doi.org/10.1016/S0033-3182(99)71229-6

de Ridder, D. T. D., \& De Wit, J. B. F. (2006). Self-Regulation and Health Behavior. Chichester: John Wiley \& Sons. http://dx.doi.org/10.1002/9780470713150

Deci, E. L., \& Ryan, R. M. (Eds.) (2002). Handbook of Self-Determination Research. Rochester, NY: University of Rochester Press.

Diotaiuti, P. (2011). Autoregolazione. Strategie Cognitive Dell'autocontrollo. Frosinone, FR: Teseo Editore.

Fredrickson, B. L. (2001). The Role of Positive Emotions in Positive Psychology: The Broaden-and-Build Theory of Positive Emotions. American Psychologist, 56, 218-226. http://dx.doi.org/10.1037/0003-066X.56.3.218

Friborg, O., Barlaug, D., Martinussen, M., Rosenvinge, J. H., \& Hjemdal, O. (2005). Resilience in Relation to Personality and Intelligence. International Journal of Methods in Psychiatric Research, 14, 29-42. http://dx.doi.org/10.1002/mpr.15

Graham, K., \& Schmidt, G. (1999). Alcohol Use and Psychosocial Well-Being among Older Adults. Journal of Studies on Alcohol, 60, 345-350. 
Hayman, K. J., Kerse, N. M., La Grow, S. J., Wouldes, T., Robertson, M. C., \& Campbell, A. J. (2007). Depression in Older People: Visual Impairment and Subjective Ratings of Health. Optometry \& Vision Science, 84, 1024-1030. http://dx.doi.org/10.1097/OPX.0b013e318157a6b1

Heyl, V., \& Wahl, H. W. (2001). Psychosocial Adaptation to Age-Related Vision Loss: A Six-Year Perspective. Journal of Visual Impairment \& Blindness, 95, 739-748.

Holman, H. R., \& Lorig, K. (1992). Perceived Self-Efficacy in Self-Management of Chronic Disease. In R. Schwarzer (Ed.), Self-Efficacy: Thought Control of Action (pp. 305-323). Washington DC: Hemisphere.

Kef, S. (2002). Psychosocial Adjustment and the Meaning of Social Support for Visually Impaired Adolescents. Journal of Visual Impairment \& Blindness, 96, 22-37.

Kemp, B. J. (2000). Psychosocial Considerations in a Rehabilitation Model for Aging and Vision Services. In J. E. Crews, \& F. J. Whittington (Eds.), Vision Loss in an Aging Society: A Multidisciplinary Perspective (pp. 133-153). New York: AFB Press.

Lazarus, R. S., \& Folkman, S. (1984). Stress, Appraisal and Coping. New York: Springer.

Levine, R. M. (2010). Identity and Illness: The Effects of Identity Salience and Frame of Reference on Evaluation of Illness and Injury. British Journal of Health Psychology, 4, 63-80. http://dx.doi.org/10.1348/135910799168470

Macfarland, D. C. (1966). Social Isolation of the Blind: An Underrated Aspect of Disability and Dependency. Journal of Rehabilitation, 32, 32-49.

Mann, M., Hosman, C. M. H., Schaalma, H. P., \& de Vries, N. K. (2004). Self-Esteem in a Broad-Spectrum Approach for Mental Health Promotion. Health Education Research, 19, 357-372. http://dx.doi.org/10.1093/her/cyg041

van der Pligt, J., \& de Vries, N. K. (1998). Expectancy-Value Models of Health Behavior: The Role of Salience and Anticipated affect. Psychology and Health, 13, 289-305. http://dx.doi.org/10.1080/08870449808406752

Verstraten, P. F. J., Brinkmann, W. L. J. H., Stevens, N. L., \& Schouten, J. S. A. G. (2005). Loneliness, Adaptation to Vision Impairment, Social Support and Depression among Visually Impaired Elderly. International Congress Series, 1282, $317-$ 321. http://dx.doi.org/10.1016/j.ics.2005.04.017

Wrosch, C., \& Schreier, M. F. (2003). Personality and Quality of Life: The Importance of Optimism and Goal Adjustment. Quality of Life Research, 12, 59-72. http://dx.doi.org/10.1023/A:1023529606137 
Scientific Research Publishing (SCIRP) is one of the largest Open Access journal publishers. It is currently publishing more than 200 open access, online, peer-reviewed journals covering a wide range of academic disciplines. SCIRP serves the worldwide academic communities and contributes to the progress and application of science with its publication.

Other selected journals from SCIRP are listed as below. Submit your manuscript to us via either submit@scirp.org or Online Submission Portal.
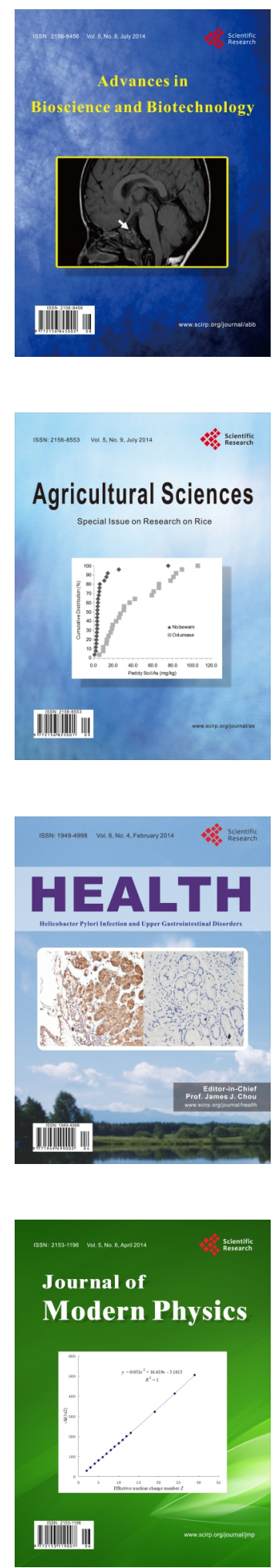
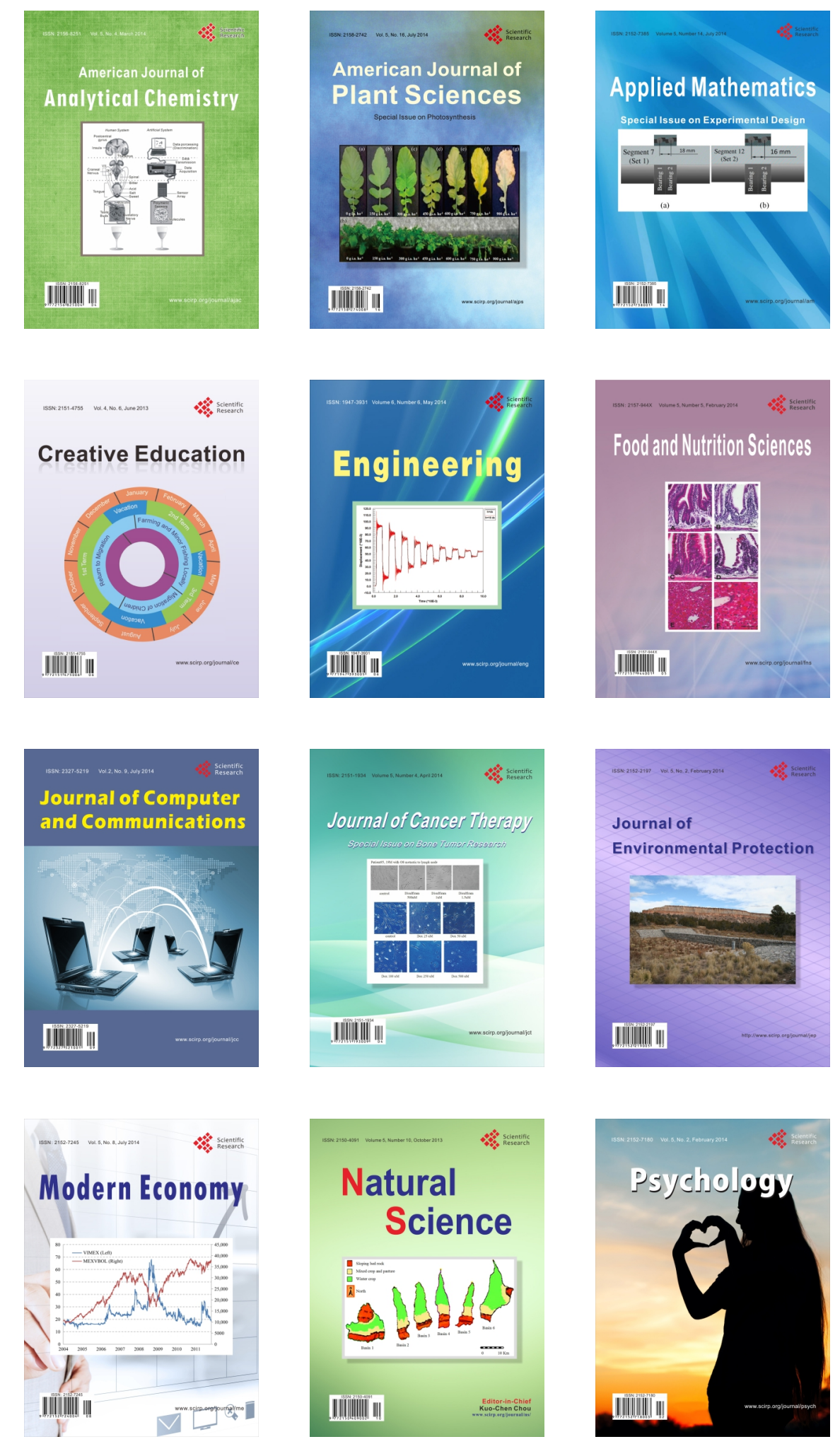